\title{
Commentary: Cafeteria diet impairs expression of sensory-specific satiety and stimulus-outcome learning
}

\author{
Shauna L. Parkes ${ }^{1,2,3 *}$, Teri M. Furlong ${ }^{4}$ and Fabien Naneix ${ }^{2,3}$ \\ 1 Institut National de la Recherche Agronomique, UMR 1286, Nutrition and Integrative Neurobiology, Bordeaux, France, \\ ${ }^{2}$ Centre National de la Recherche Scientifique, UMR 5287, Institut de Neurosciences Cognitives et Intégratives d'Aquitaine, \\ Bordeaux, France, ${ }^{3}$ Université de Bordeaux, UMR 1286 and UMR 5287, Bordeaux, France, ${ }^{4}$ Department of Neurobiology \\ and Anatomy, University of Utah School of Medicine, Salt Lake City, UT, USA
}

Keywords: diet, sensory-specific satiety, Pavlovian, decision making, obesity

\section{A commentary on}

Cafeteria diet impairs expression of sensory-specific satiety and stimulus-outcome learning by Reichelt, A. C., Morris, M. J. and Westbrook, R. F. (2014). Front. Psychol. 5:852. doi: $10.3389 /$ fpsyg.2014.00852

OPEN ACCESS

Edited by:

Marion Hetherington,

University of Leeds, UK

Reviewed by:

Ashley Martin

University of Bristol, UK

Pam Blundell,

University of Leeds, UK

*Correspondence:

Shauna L. Parkes,

shauna.parkes@u-bordeaux.fr

Specialty section:

This article was submitted to

Eating Behavior,

a section of the journal

Frontiers in Psychology

Received: 04 February 2015

Accepted: 14 April 2015

Published: 30 April 2015

Citation:

Parkes SL, Furlong TM and Naneix F (2015) Commentary: Cafeteria diet impairs expression of sensory-specific

satiety and stimulus-outcome learning. Front. Psychol. 6:536 doi: 10.3389/fpsyg.2015.00536
Current global estimates indicate that the proportion of adults meeting the criterion for overweight and obesity is $40 \%$, with this proportion expected to increase ( $\mathrm{Ng}$ et al., 2014). Thus, diet is arguably the largest controllable factor related to the burden of disease, yet changing dietary habits is notoriously difficult (Caballero, 2007) and the reason for this is unknown. Mounting evidence suggests that, in addition to contributing to the unprecedented rates of obesity worldwide (Caballero, 2007), the consumption of high fat, high sugar (HFHS) diets is associated with a range of cognitive impairments in humans (Smith et al., 2011; Gustafon et al., 2012) and non-human animals (Beilharz et al., 2014; Reichelt et al., 2015). Such data raise the possibility that intake of calorically dense foods may alter cognitive capacities critical for food-related decision making and, as a result, make it more difficult for individuals to change their eating behaviors.

In a recent issue of Frontiers, Reichelt et al. (2014) examined the effect of a highly palatable and caloric rich ("cafeteria") diet on food-related cognition in rodents. Specifically, they used Pavlovian devaluation to determine if consumption of a cafeteria diet affects the ability to learn about foodrelated stimuli. Rats were trained to associate two cues with two distinct foods after which one of the foods was devalued via sensory-specific satiety, defined as a rejection of a food recently eaten to satiety while readily consuming another food with distinct sensory properties (Rolls, 1986). Rats fed a standard chow diet responded less during the stimulus that predicted the devalued food than during the stimulus that predicted the still valued food. In contrast, cafeteria-fed rats responded equally during both stimuli. Based on this result, the authors conclude that consumption of the cafeteria diet produces a deficit in the expression of stimulus-outcome learning and, in particular, of cue-food associations.

However, in addition to the deficit observed in Pavlovian devaluation, the authors also reported that, following satiety-induced devaluation, cafeteria-fed rats failed to show sensory-specific satiety and consumed equal amounts of the devalued and valued foods. Indeed, following selective satiation, cafeteria-fed rats reduced their consumption of both the devalued and valued foods. As such, the authors have provided clear evidence that satiety-induced devaluation was not effective in selectively reducing the value of the prefed food in the cafeteria-fed rats. The reliance on this 
devaluation treatment in the Pavlovian task therefore poses a considerable confounding factor. Specifically, the deficit observed may not reflect impaired stimulus-outcome learning, as suggested by the authors, but instead could be attributable to the cafeteria-fed rats' insensitivity to selective satiety-induced devaluation. To assess if consumption of a cafeteria diet impairs the ability to learn and express cue-food associations a task that can selectively devalue the prefed food should be used, for example, lithium chloride-induced devaluation (Holland and Straub, 1979; Singh et al., 2010). Alternatively, a Pavlovianinstrumental transfer task could be used to evaluate the capacity of a food-related stimulus to invigorate responding for a specific food (Corbit and Balleine, 2003). Both of these procedures allow the assessment of stimulus-outcome associations in cafeteria-fed rats independently of the observed deficit in sensory-specific satiety.

Using a similar devaluation procedure, Furlong et al. (2014) recently reported that consumption of a HFHS diet promotes habitual food-seeking. However, in contrast to Reichelt et al, Furlong and colleagues reported no effect of the diet on sensoryspecific satiety. Rats with and without a history of a HFHS diet consumed more of the valued than the devalued food when the foods were freely available, indicating that altered food-seeking behavior was not secondary to compromised specific satiety and was instead due to altered learning. The difference in sensitivity to specific satiety-induced devaluation reported by the two studies is striking. While there were a number of small procedural differences (e.g., choice vs. non-choice of the valued and devalued food, time between devaluation and the sensory-specific satiety test), there was also an important difference in the accessibility of the high calorie diets. Specifically, Reichelt et al. used continuous access whereas Furlong and colleagues used intermittent access. It is not immediately clear why continuous versus intermittent access would differentially affect sensory-specific satiety however, it is reasonable to speculate that animals with continual access to a high calorie diet may become less sensitive to the immediate sensory impact of food. Studies examining the adaptation of

\section{References}

Avena, N. M., Long, K. A., and Hoebel, B. G. (2005). Sugar-dependent rats show enhanced responding for sugar after abstinence: evidence of a sugar deprivation effect. Physiol. Behav. 85, 359-362. doi: 10.1016/j.physbeh.2004. 12.016

Balleine, B. W., and O'Doherty, J. P. (2010). Human and rodent homologies in action control: corticostriatal determinants of goal-directed and habitual action. Neuropsychopharmacology 35, 48-69. doi: 10.1038/npp. 2009.131

Beilharz, J. E., Maniam, J., and Morris, M. J. (2014). Short exposure to a diet rich in both fat and sugar or sugar alone impairs place, but not object recognition memory in rats. Brain Behav. Immun. 37, 134-141. doi: 10.1016/j.bbi.2013.11.016

Caballero, B. (2007). The global epidemic of obesity: an overview. Epidemiol. Rev. 29, 1-5. doi: 10.1093/epirev/mxm012

Clifford, C. W., Webster, M. A., Stanley, G. B., Stocker, A. A., Kohn, A., Sharpee, T. O., et al. (2007). Visual adaptation: neural, psychological and computational aspects. Vision Res. 47, 3125-3131. doi: 10.1016/j.visres.2007. 08.023 sensory systems indicate that repeated exposure to the same stimulus results in an attenuated neural response to that stimulus and a diminished perceptual experience (Clifford et al., 2007; Webster, 2012). Indeed, chronic exposure to a high calorie diet induces a decrease in both the consumption of palatable foods (Duca et al., 2014) and in hedonic reactions to these foods (Shin et al., 2011). Moreover, a number of studies have reported differential effects on cognition depending on the nature of the access to the diet (Colantuoni et al., 2002; Avena et al., 2005; Furlong et al., 2014; Martire et al., 2014). For example, intermittent, but not chronic, access to a high calorie diet promotes habitual food-seeking (Furlong et al., 2014) and bingelike eating patterns (Martire et al., 2014). Given these differences in accessibility of high calorie foods it cannot be assumed that the diet used by Reichelt and colleagues would necessarily result in deficits in the learning and expression of food-cue associations, but the question warrants further investigation.

Increasing evidence suggests that consumption of calorically rich foods leads to changes in cognitive control which makes subsequent changes to eating behaviors more difficult. Research into the nature of these cognitive deficits is therefore highly valuable for instantiating changes in eating behaviors to combat the obesity epidemic. Reichelt and colleagues have provided important evidence that continuous exposure to a Western-style diet disrupts sensory-specific satiety, an effect that, in humans, may result in over-consumption of food (Hetherington, 1996). However, it still remains to be determined if such diets also impair learning about food-related cues, a result that has more far-reaching consequences for effective dieting strategies and decision making in general (Balleine and O'Doherty, 2010).

\section{Acknowledgments}

The authors wish to thank Dr. Etienne Coutureau for his comments on an earlier version of this manuscript. The authors are supported by INRA and Agreenskills (SLP), Fonds Français Alimentation Sante (FN) and NIH MH094870 (TMF).

Colantuoni, C., Rada, P., McCarthy, J., Patten, C., Avena, N. M., Chadeayne, A., et al. (2002). Evidence that intermittent, excessive sugar intake causes endogenous opioid dependence. Obes. Res. 10, 478-488. doi: 10.1038/oby.2002.66

Corbit, L. H., and Balleine, B. W. (2003). Instrumental and Pavlovian incentive processes have dissociable effects on components of a heterogeneous instrumental chain. J. Exp. Psychol. Anim. Behav. Process. 29, 99-106. doi: 10.1037/0097-7403.29.2.99

Duca, F. A., Swartz, T. D., and Covasa, M. (2014). Effect of diet on preference and intake of sucrose in obese prone and resistant rats. PLOS ONE 9:e111232. doi: 10.1371/journal.pone.0111232

Furlong, T. M., Jayaweera, H. K., Balleine, B. W., and Corbit, L. H. (2014). Binge-like consumption of a palatable food accelerates habitual control of behavior and is dependent on activation of the dorsolateral striatum. J. Neurosci. 34, 5012-5022. doi: 10.1523/JNEUROSCI.370713.2014

Gustafon, D. R., Backman, K., Joas, E., Waern, M., Ostlin, S., Guo, X., et al. (2012). 37 years of body mass index and dementia: observations from the prospective population study of women in Gothenburg, Sweden. J. Alzheimers. Dis. 28, 163-171. doi: 10.3233/JAD-2011-110917 
Hetherington, M. M. (1996). Sensory-specific satiety and its importance in meal termination. Neurosci. Biobehav. Rev. 20, 113-117. doi: 10.1016/01497634(95)00048-J

Holland, P. C., and Straub, J. J. (1979). Differential effects of two ways of devaluing the unconditioned stimulus after Pavlovian appetitive conditioning. J. Exp. Psychol. Anim. Behav. Process. 5, 65-78. doi: 10.1037/0097-7403.5.1.65

Martire, S. I., Westbrook, R. F., and Morris, M. J. (2014). Effects of long-term cycling between palatable cafeteria diet and regular chow on intake, eating patterns, and response to saccharin and sucrose. Physiol. Behav. 139, 80-88. doi: 10.1016/j.physbeh.2014.11.006

Ng, M., Fleming, T., Robinson, M., Thomson, B., Graetz, N., Margono, C., et al. (2014). Global, regional, and national prevalence of overweight and obesity in children and adults during 1980-2013: a systematic analysis for the Global Burden of Disease Study 2013. Lancet 384, 766-781. doi: 10.1016/S01406736(14)60460-8

Reichelt, A. C., Maniam, J., and Westbrook, R. F., Morris, M. J. (2015), Dietary-induced obesity disrupts trace fear conditioning and decreases hippocampal reelin expression. Brain Behav. Immun. 43, 68-75. doi: 10.1016/j.bbi.2014.07.005

Reichelt, A. C., Morris, M. J., and Westbrook, R. F. (2014). Cafeteria diet impairs expression of sensory-specific satiety and stimulus-outcome learning. Front. Psychol. 5:852. doi: 10.3389/fpsyg.2014.00852

Rolls, B. J. (1986). Sensory-specific satiety. Nutr. Rev. 44, 93-101. doi: 10.1111/j.1753-4887.1986.tb07593.x
Shin, A. C., Zheng, H., Pistell, P. J., and Berthoud, H. R. (2011). Roux-en-Y gastric bypass surgery changes food reward in rats. Int. J. Obes. 35, 642-651. doi: 10.1038/ijo.2010.174

Singh, T., McDannald, M. A., Haney, R. Z., Cerri, D. H., and Schoenbaum, G. (2010). Nucleus accumbens core and shell are necessary for reinforcer devaluation effects on Pavlovian conditioned responding. Front. Integr. Neurosci. 4:126. doi: 10.3389/fnint.2010.00126

Smith, E., Hay, P., Campbell, L., and Trollor, J. N. (2011). A review of the association between obesity and cognitive function across the lifespan: implications for novel approaches to prevention and treatment. Obes. Rev. 12, 740-755. doi: 10.1111/j.1467-789X.2011.00920.x

Webster, M. A. (2012). Evolving concepts of sensory adaptation. F1000 Biol. Rep. 4:21. doi: 10.3410/B4-21

Conflict of Interest Statement: The authors declare that the research was conducted in the absence of any commercial or financial relationships that could be construed as a potential conflict of interest.

Copyright (c) 2015 Parkes, Furlong and Naneix. This is an open-access article distributed under the terms of the Creative Commons Attribution License (CC BY). The use, distribution or reproduction in other forums is permitted, provided the original author(s) or licensor are credited and that the original publication in this journal is cited, in accordance with accepted academic practice. No use, distribution or reproduction is permitted which does not comply with these terms. 